\title{
The history of health technology assessment in Norway
}

\author{
Berit Mørland \\ The Norwegian Knowledge Centre for the Health Services
}

\begin{abstract}
Objectives: The aim of this study was to describe the Norwegian contribution to the broad picture of our international health technology assessment (HTA) history.

Methods: A general examination of some pre-HTA activities, as consensus conferences, closer reading of all background papers to the establishment of an HTA agency in Norway, the ongoing activities of this agency, its evaluation, and its merge into a broader knowledge center for the health services were performed. All information and statements are the authors' own understandings, but also were reviewed by some of the people taken part in these processes.

Results: The Norwegian HTA activity was set up rather late compared to, for instance, Sweden, and our involvement in Nordic early warning activities. This may be related to Norwegian scientists being more involved in the Cochrane Collaboration. However, when established, the HTA agency was regarded as highly successful in involving clinical experts and responding to questions arising from the macro- as well as micro-levels of decision makers. International collaboration was essential in building the capacity to serve all levels. After 6 years, the agency was merged with some related health service knowledge activities, into a new center.
\end{abstract}

Conclusions: During the 10 years' time, HTA has become a well-established activity in Norway.

Keywords: Health technology assessment, Agency, History

From the middle of the 1980s, the Norwegian Medical Research Council (MRC) started to organize Consensus Conferences as part of their dissemination and implementation policy. The author was the head of the Council at that time. The idea and background for making use of consensus conferences was drawn from the National Institutes of Health, United States (12). The main reason behind the organizing of conferences in Norway was the MRC's wish to use scientific contributions to solve problems of great controversy among the healthcare providers. Typical themes were HRT treatment to menopausal women, mammography screening, use of ultrasound during pregnancy, and so on. By taking on this role, the MRC was more actively influencing the health care, than just financing research projects. To some aspect, it was also a precursor to the technology assessment way of working. As part of that work, interest was also raised in evidence-based medicine (EBM) and the Cochrane Collaboration. This interest was shared with people from the other Nordic countries, among them Egon Jonsson, Lars Werk $\varnothing$, and Tore Schersten (Chair of MRC) from Sweden, where this interest was supporting the establishment and work at SBU in Sweden (1988). However, nothing similar happened in Norway at that time.

In Norway, a more active involvement in the Cochrane Collaboration, which had been established in 1992, started among researchers at the Norwegian Public Health Institute. Important in this work was Arild Bjørndal, who later on managed to recruit Andy Oxman to this work in Norway. The Norwegian Branch of the Nordic Cochrane Collaboration Centre in Copenhagen was established. This resulted in more focus on the Cochrane activities in Norway in the 1990s, than was the case in Sweden, which focused on health technology assessment (HTA) and SBU.

The MRC did, however, continue its program on consensus conferences, and also took up a somewhat linked project on early warnings (17). The main motivating force in this work in Norway was Hroar Piene, working together with colleagues in Sweden and Denmark.

In 1995, the Norwegian Ministry of Health and Social Affairs (SHD) appointed a working group to discuss HTA, 
also in Norway. This initiative was to some extent pushed by the people working on early warning processes in the Medical Research Council. The working group was headed by SHD, and was asked to define HTA, also related to the Cochrane activities, and to present opportunities for organizing HTA activity in Norway.

The group did site visits to the United Kingdom (DOHR\&D, NHSCRD York), Sweden, (SBU), Denmark, and the Netherlands. They recognized the same need for documentation to meet the information overload from research, clinical experts, industry, patients' expectations, and so on. The conclusion from the working group was that "Norway will need a permanent organization evaluating new as well as established technologies or methods used in the health care; and assessing their effectiveness, risks, and costs in a systematic way" (16). The conclusion was presented to the Parliament as part of the financial plan for 1997, St prp 1 (1996-97).

The Norwegian health system has two levels: the municipal health service, responsible for doctors (general practitioners, GP), nursing homes, and health stations, and the central government level responsible for hospitals and the other specialist services. The GPs get their reimbursement from the social service system. The healthcare system is free for everyone and publically financed as part of the tax payer system, with a small individual fee per consultation. Everyone is in principle secured ready access, but a priority setting system has been introduced, depending on the seriousness of the disease.

HTA was first of all meant to serve the management and clinical levels of the system with best evidence on new technologies, before they were taken into use. The important issue was the clinical effectiveness of the technology. At the same time, the healthcare expenditure also started to rise more then the Norwegian governments had seen before, and cost-effectiveness assessments became increasingly important to get more information and control.

\section{ESTABLISHMENT OF THE NORWEGIAN HTA CENTRE-1998}

As often is the case, a discussion followed on where and how this "permanent organization" was to be established. A research-based setting at a medical faculty or a more clinician-based setting at the National Hospital were the most actual alternatives. The then Minister of Health Gudmund Hernes stated, however, the importance that this center should be, and be regarded as, independent by medical researchers as well as clinicians, and also to be housed outside the central health administration.

It was, therefore, decided to establish the Norwegian HTA Centre at an independent research foundation, SINTEF, the largest technological and social science research foundation in the Nordic countries. The establishment of the Senter for medisinsk metodevurdering (SMM) was based on an agreement between SINTEF and the SHD as a 3-year trial project, in 1997. The Ministry contributed financially, and was responsible for appointing the Board of Directors, but had no means to direct or modify the work.

SINTEF turned out to be a very good place to house the Norwegian HTA activity. The SMM organization was supported with necessary administrative and management facilities, but was otherwise free to establish the center according to its aims and objectives. The new organization should not have a mandate to give recommendations, develop guidelines, start clinical trials or decide in politics, but should establish the scientific evidence for clinical effects, cost-effectiveness, and highlighting other issues of relevance. The specific objectives of the Centre, as expressed in the Parliamentary propositions, in the agreement between the SHD and SINTEF and SMM's own operational approaches, were as follows:

(i) identify needs for assessment; (ii) perform the assessments, including documentation of effects, costseffectiveness, and values; (iii) establish national expert groups, and join relevant international networks; (iv) give advice and education on the working methods used in the HTAassessment; (v) take part in implementation and follow-up of the assessment results; and (vi) inform the health authorities (macro), managements (meso), as well as clinical and research (micro) levels about the HTA and the results from the assessments performed.

The Norwegian Centre for Health Technology Assessment (SMM) was the start of the first and only HTA agency in Norway. During the first couple of years, the staff of the center was established as a multidisciplinary team with medical, social, and science background, health economics, ethical, and information knowledge (10-12 scientists). The Director, responsible for setting up the SMM, was Berit Mørland. The Centre's Board of Directors and a consulting panel of 60 experts represented a range of health institutions, universities, hospitals, central health administration, and professional and patient organizations. The first Chair of the Board of Directors was Professor of Surgery Odd Søreide.

Suggestions of topics were received from ministries, hospitals, clinicians, and patients. The selection of topics to be further evaluated was made by the Board of Directors, using the following criteria: the burden of the disease, variation in clinical practice and disagreement among experts, economical consequences, relevance (for policymakers) and that some documentation was available (although it was also realized that information about little or no documentation might be important).

Expert groups (review teams) led by SMM staff using international principles of HTA in their work formed the major working method $(8 ; 11 ; 13)$. The range of disciplines was founded in the need to make sure the literature assessment was relevant and of highest quality. The members of the teams gained knowledge of the methods used in making systematic reviews, and could, therefore, bring this knowledge back into their own workplace. As they were often chosen on 
a background of being "opinion leaders" in their field, they were important in the challenging work of implementing the results and assist in increasing the impact by having the full knowledge of how the work was undertaken. In this way was achieved knowledge dissemination of HTA as a working method and of the results of the subject under study (9).

The SMM products were HTA reports (systematic reviews), overviews of international HTAs or systematic reviews, and early warning reports.

SMM perhaps pointed more at the clinical/microdecision level, than most other HTA agencies. The report on hip replacement prosthesis revealed that more than fifty different types were in use in Norway and that more than a third of these lacked sufficient scientific evidence on clinical results (14). Another report that made an impact on changes in the service was that on the use of percutaneous coronary intervention (PCI) where a meta-analysis of seventeen studies showed reduced mortality, re-infarction and stroke (18). However, also some questions were raised by the health policy (macro) level, that is, the documented clinical outcomes from using positron emission tomography (PET) as a diagnostic procedure, and the possible future need for PET in Norway (10). A series of reports on treatment volumes and patient outcomes were initiated from the SHD.

The reports were published and presented at dedicated seminars and national/international conferences, a Web-page was established, and a newsletter published regularly; all using a publication profile that was made early in the project making the products easily recognizable.

In summary, this multilevel way of organizing and disseminating the work ensured a spread of knowledge of HTA in Norway. What started as a 3-year trial project proved a sustainable working method.

\section{INTERNATIONAL COLLABORATION}

It was stated as part of the objectives that the center should join relevant international networks, and this turned out to be a large and a very important part of SMMs work.

As a new entity, responsible for a new national activity, it was quite essential for the work to draw on other agencies' and colleagues' experiences and advices. Some of those who provided help and support in the early phase of HTA in Norway were Tore Schersten and Egon Jonsson from SBU (Sweden), John Gabbay from NCCHTA (Southampton, UK), Jos Kleijnen, NHSCRD (York UK), Alicia Granados (CAHTA, Spain), Bernhard Xerri (ANAES France), Jill Sanders (CCOHTA, Canada), and the heads of the Nordic sister-agencies; Finn Børlum Kristensen, Risto Roine, Marjukka Mäkela, and Nina Rehnquist. Involved with all, and with a complete international overview, was the Office of Technology Assessment veteran and President of International Society of Technology Assessment in Health Care (ISTAHC), David Banta.
International collaboration is very much appreciated and is an integral work in HTA. The exchange of knowledge has been important for our publication in the scientific journal International Journal of Technology Assessment in Health Care. We got our individual memberships in ISTAHC, which was reorganized in 2002 into Health Technology Assessment international (HTAi). Perhaps most important for the development of SMM as an HTA agency was our early membership of INAHTA (International Network of Agencies for Health Technology Assessment). We experienced that an increasing numbers of organizations throughout the world assessed healthcare technology. There was an evident need to cooperate and share information. INAHTA served this purpose, and SMM went through a phase of just learning, to also become able to share our experiences and advice with others. We also became a partner for WHO Europe's Health Evidence Network (HEN). We served as the Norwegian delegate in the Organisation for Economic Co-operation and Development Project on New and Emerging Health related technologies, where the reasons for undertaking HTA by case study technologies were evaluated (15). SMM took part in the European research programs: HTA-Europe (1997-98) and ECHTA/ECAHI (2000) (6). The work is now being taken further by the Norwegian Knowledge Centre for the Health Services; see below, in the network of HTA-agencies called European Network for Health Technology Assessment (EUnetHTA) (3).

\section{HTA CENTRE (SMM): 6 YEARS}

The work at SMM resulted in a total of thirty-one reports; eighteen commissioned from external sources, primarily the SHD, and thirteen from SMMs Board of Governors or by the panel of advisors (mostly clinical experts).

SMM made no preferences as to which medical field would be of interest. One or more appraisal themes were included for most reports. Twenty-four reports presented information on relevant Norwegian practice such as rate of prostate-specific antigen tests for prostate cancer evaluation, and distribution among hospitals of specific kinds of surgery. Health economic analyses were included in twenty-one reports ranging from information on DRG, presenting simulation analyses and quality-adjusted life-year calculations in cost-utility analyses. SMM established a separate unit for health economy consisting of a health economist, social economist, and statistician to cover cost-effective analysis. A discussion around ethical considerations was included in thirteen reports. SMM employed a specialist in medical ethics, who was working toward a procedure ("checklist") for integrating moral/ethical issues in HTA (5). Organizational issues were of interest for seventeen reports. Legal implications were few and discussed in six reports only.

The most important regulatory mechanisms for the healthcare systems in Norway are the government (SHD) financing and presenting aims and working plans to the 
hospitals, and the municipalities with similar responsibility for the primary care. The hospitals, organized into four Regional entities with their own Boards, have great regional freedom, and GPs have freedom when treating individual patients. They must, however, take into account decisions from The Medicines agency, which is responsible for regulating and reimbursement of drugs, and the Directorate for Health and Social affairs being responsible for National Guidelines. These guidelines are only advisory, and covering rather broad topics, as handling of diabetes, pregnancy care, and so on. The introduction of new technology (procedures, devices, drugs in hospitals) is essentially not regulated in any way, except for CE-marks for devices. Very often this kind of introduction into the health services is promoted by individual clinicians and providers. It is claimed that this situation is partly responsible for the high rise in the Norwegian healthcare budget, and probably part of the reason behind the establishment of HTA in Norway. (A new project has been set up (2008) by the Ministry to establish a system for introducing new and costly technologies into the Norwegian hospital sector.)

We have been publishing the impact from the reports on the problem areas of the health services which they addressed (7). In general, we found that the reports have had an impact on the use of medical technologies on national and professional level. The subject of the reports ought to address areas that were in due course for a change and for which it was possible to give a direction for change. The implementation of the results was not found to be dependent on the commissioner being external or internal. However, we experienced that impact was greater on the policy makers at the macro and meso levels. More effort was in general needed to make an impact at the clinical (micro) level The impact of the conclusions of the reports has been multiple. In all, twelve reports of the thirty-one influenced national procedures such as the establishment of PET technology in Norway. Two national guidelines were altered. Distribution of duties was changed as a result of the reports such as treatment with PCI in myocardial infarctions. Clinical guidelines were changed due to four reports. In three reports, there was advised no change in practice and of seven we had no information. One health economic report did not alter the introduction of a new kind of prescription (on physical activity), although the costeffectiveness results did not support it. When going through all the reports and their possible impact, we found that they exerted their impact most likely within the first 6 months after publication,

Our conclusions are as follows: (i) The topic should be seen in a clear decision-making process (macro- or microlevel); (ii) It should involve opinion leaders; (iii) Independence (no political or professional interests) must be clearly shown; (iv) The responsibility of achieving impact should be shared with the users of HTA; and (v) A wide range of strategies, tailor-made for the users, may be more effective than a single one.
SMM also established an early warning activity. This was greatly inspired and supported by the Centre's membership in Euroscan. We observed an increasing demand from our commissioners to evaluate new (and costly) technologies before they were introduced into the Norwegian healthcare system. The most frequent requests came from hospital managements and from the Medicines Control Agency. SMM made use of international sources: Horizon Scanning Centre (UK), Euroscan and INAHTA. The results were presented to national expert groups who were evaluating the international information before published by SMM

\section{EVALUATION}

The establishment of the SMM was based on an agreement between the Ministry of Health and Social Affairs and SINTEF, see above. As part of this agreement, SMM should be evaluated at the end of the first 3-year period. In the contract description issued by the Ministry, it was stated that the evaluation of the Centre must be based on this agreement, and, furthermore, the evaluators were requested to rule on the following six conditions: (i) To what extent is the organization of the Centre appropriate with regard to the mandated assignment? (ii) How appropriate is the process for identification and prioritization of themes for technology assessment? (iii) How appropriate is the work process (method) and quality of the finished report? (iv) To what degree are the various professional communities included and used in the work project? (v) Information strategy, including the presentation format. (vi) The participation of the Centre in national and international networks (collaboration and work-sharing).

A request was also made for a "forward strategy," including assessment of the placement of the SMM, and the terms and conditions that would allow SMM to function within the context of a possible future comprehensive system for assessment of medical methods in Norway. The evaluation was performed by scientists from a Norwegian research institute (NIFU) with great competence in evaluation procedures (1).

Some of their answers to the Ministry's request were as follows.

(i) SMM has established a reasonably well-balanced assignment portfolio that includes both traditional technologies assessment and assessment of new technologies. The Centre should actively work to expand its client base to include also the responsible authorities for the regional/municipal health departments. SMM should place greater emphasis on pharmaceutical treatments. The staff should be enlarged and reinforced, in the nonmedical areas as well, such as economics and ethics. The management team should maintain its professional function, but it should place greater emphasis on strategic planning and setting priorities. The Centre must be assured a stable and adequate funding base so that it is not dependent on funds from contractors.

(ii) The criteria and procedures established at SMM for the selection and prioritizing of work assignments should fully satisfy the mandate that the Centre is charged to carry out. 
(iii) SMM's products are in all respects of a high quality, and SMM's technology assessments have a good international reputation. Discussions regarding the data base of the technology assessments are sometimes insufficient, and there is not always a good correspondence between analyses and conclusions.

(iv) SMM has been successful in establishing a solid national network of professional experts. However, in future, it should place more emphasis on acquiring expertise from the operational levels, including general practitioners, and nursing in care-giving functions. The role of professional experts should be discussed further in the light of their lack of competence in technology assessment. To ensure legitimacy, the professional experts requested to submit a statement in which they declare any possible conflict of interest.

(v) SMM's information strategy has been very successful, especially with respect to the central health-political authorities.

(vi) SMM is an active participant in the international network concerned with technology assessment. The Centre should in the future look further into whether there will be clear synergistic effects in having a more formalized collaboration with the Nordic sister organizations.

Forward strategy: Considered as a separate unit, there is no reason for changing the organizational placing within SINTEF. However, the evaluators will recommend that competence for medical technology assessment be assembled under a single Centre in Norway.

This evaluation was accomplished after SMM's initial 3 years, and many of the recommendations were followed-up in the coming years; that is, increased use of health economics and ethical analysis, more studies on pharmaceuticals, more focus on general practitioners and other healthcare workers, and so on.

The comment on forward strategy from the evaluators was related to a general reorganization of the public health authorities in Norway at this time (2002-03), where one proposal was to move SMM into the newly established Directorate for Health and Social Affairs. SMM was very much against this proposal, fearing that this would greatly reduce its professional and scientific independence. The Ministry took these concerns into consideration, and withdrew this proposal. Instead, a new professionally and scientifically independent center was established, see below.

\section{THE NORWEGIAN KNOWLEDGE CENTRE FOR THE HEALTH SERVICES-2004}

SMM was reorganized in 2004 and merged with two related organizations into the Norwegian Knowledge Centre for the Health Services (NOKC). Included in the organization were, together with SMM, a division from the Directorate for Health and Social affairs, now including the Norwegian Branch of the Nordic Cochrane Collaboration Centre, and a research institute (HELTEF) dedicated to patient satisfaction surveys and quality measurements. Later on, an Internet
Health Library with links to publications and databases of literature was established; the secretariat for the Campbell Collaboration and a Patient safety unit have been included.

The new Centre was organized under The Directorate for Health and Social Affairs, but was to stay autonomous and professionally independent — of government, industry, and professions. The head of the HELTEF, John-Arne Røttingen, was appointed Director of the Centre, and Berit Mørland from SMM Deputy Director.

The Knowledge Centre was set up with a Scientific Council, but no Board. It reports to the Directorate (i.e., the "Board" function). The Centre has no formal authority, no normative functions, but was established as a knowledge brokering institution in the Norwegian health system to help inform policy decision processes and clinical policy making. The Centre summarizes and disseminates evidence concerning the effect of treatments, methods, and interventions in the health services, in addition to monitoring health service quality.

After the fusion the new center consisted of approximately 70-80 employees, this figure has now risen to 125 , of whom 50-60 scientists are working within a broad field of HTA.

The Centre gets its main working directives through the yearly parliamentary financial plan, but within this context a procedure for prioritization of single assessments are set up. All relevant actors (public stakeholders/commissioners/clinicians/patients) can ask for reports from the Centre. The main commissioners (Directorate, Regional hospital authorities, Medicines agency, and professional societies) are formally involved in the prioritization process.

The Knowledge Centre has, through SMM, a long tradition in supporting healthcare decision making, and has carried on the various challenges of producing HTAs for different levels: macro (policy makers in ministry and directorate), meso (institutions), and micro (practitioners, patients).

\section{DISSEMINATION AND IMPLEMENTATION}

To facilitate the use of best evidence in both policy making and clinical practice, an electronic Health Library, available to all health professionals, has been established. The Library offers free access to a large number of databases and scientific journals as well as information about HTAs, systematic reviews, guidelines, and so on (www.helsebiblioteket.no). Universities and regional colleges are supported in their efforts to include evidence based practice, patient safety, and quality improvement in their programs, by scientists at the Knowledge Centre who also serve as part-time teachers. An open-access database for early assessment of new technologies (MedNews) is published (www.mednytt.no).

In addition, the Centre has been given a more indirect influence on policy making as Secretariat for the newly established Norwegian Council for Quality Improvement 
Pharmaceuticals in Norway

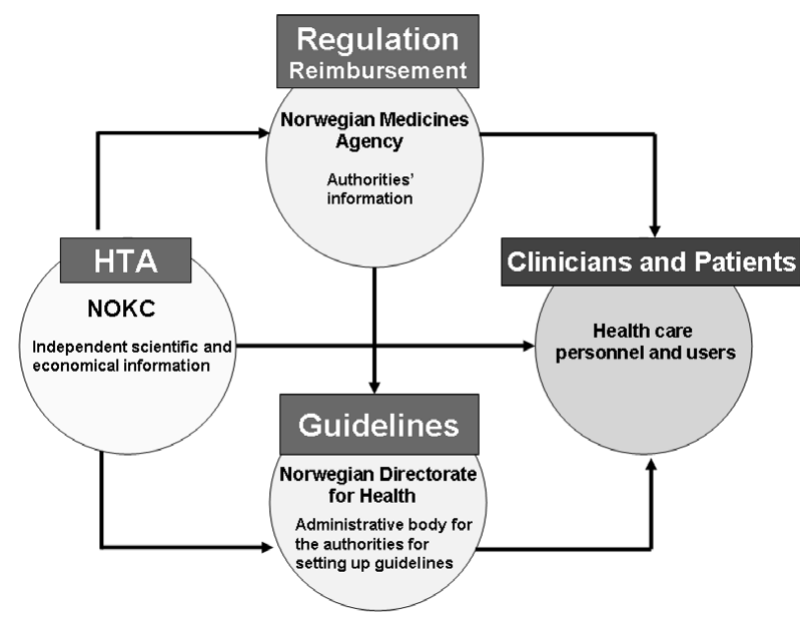

Figure 1. Pharmaceuticals in Norway. HTA, health technology assessment; NOKC, Norwegian Knowledge Centre for the Health Services.

and Priority Setting in Health Care (www. kvalitetogprioritering.no). The Council's mission is to advise on decisions in health care, for instance, on introduction of new (and costly) technologies, by basing the discussions and their conclusions on the best documented evidence, most often in the form of HTA reports.

\section{INTERNATIONAL COLLABORATION}

Managers and scientists from NOKC have continued to take actively part in international networks, and have also been elected to chairing positions and as delegates in Boards and steering groups. Output from these network discussions still has implications on how we develop HTA to best serve decision making on related topics (i.e., the introduction and reimbursement of new technology) in Norway. An important accomplishment has been the formal establishment of collaboration between the Medicines Agency, the Directorate for Health, and NOKC, where the interplay among the different bodies involved in knowledge production, approval, and policy decisions on pharmaceuticals is illustrated in Figure 1.

\section{NOKC Products}

Presently the Knowledge Centre operates with the following "products": HTA reports, early warning reports, systematic reviews (Cochrane), electronic health library, performance indicators, clinical indicators, quality improvement advice, and patient safety.

NOKC increased the number of completed HTA reports, totaling forty-three reports over a 4-year period (2004-07) as a result of increasing number of staff. The commissions have to a large extent changed from SMMs, as many are now channeled through the Directorate for Health and Social Affairs. An increasing number is coming from the newly established Regional Hospital Boards. NOKC has put an even increasing emphasis on health economic issues, as this perspective increasingly concerns the best use of resources in the health service.

The majority of reports from SMM were on effects of treatments. In NOKC, there are also assessments on prevention, reflecting the high number of requests from the Directorate for Health and Social Affairs. There are also increasing interests in using HTA for organizational matters in the healthcare system (Regional Hospital Boards).

\section{Evaluation}

Similar to SMM, NOKC was set up under the understanding that the Centre was to be evaluated after the first 2-3 years. An evaluation group consisting of experts from Sweden and Norway was working on behalf of the Directorate for Health and Social Affairs, and asked to answer very similar questions as the SMM evaluators (2).

The external evaluation underlined that the establishment of the Centre has formed part of a national strategy to ensure that the necessary evidence base for decision making in health care is available in Norway. The Centre was considered to be a successful effort with good results in terms of its width, initiatives and vitality. Some concern was raised to the Centre moving into new fields previously served by others, which has lead to a certain reservation within the health service and in those affected, which has also had impact on their view on the Centre's core activity, systematic summaries, and HTAs.

Another concern was a lack of clinical and regional links, and a regional network strategy for the further development of the Knowledge Centre was suggested. This suggestion may be taken forward to build up regional "HTA nodes" also in Norway; similar to what has happened in the other Nordic countries.

\section{DISCUSSION}

During the 10 years' time while HTA has become a well established activity in Norway, we have seen great changes nationally as well as internationally. In retrospect, I can see that our strategies in some aspects functioned very well, whereas in others we might have done better or otherwise.

International collaboration is in any case the foundation of HTA, and was essential for our work nationally. It has become even more important, and with a broadened perspective. The basic methodology is still in focus, for instance as a common "core" in EUNetHTA (4), but the use of HTA and the involvement of users have become more important. The strategic discussions that took place at the founding of HTAi opened up the Society to be a place for users as well as doers. 


\section{Knowledge Chains $\longrightarrow$ Knowledge Brokering}

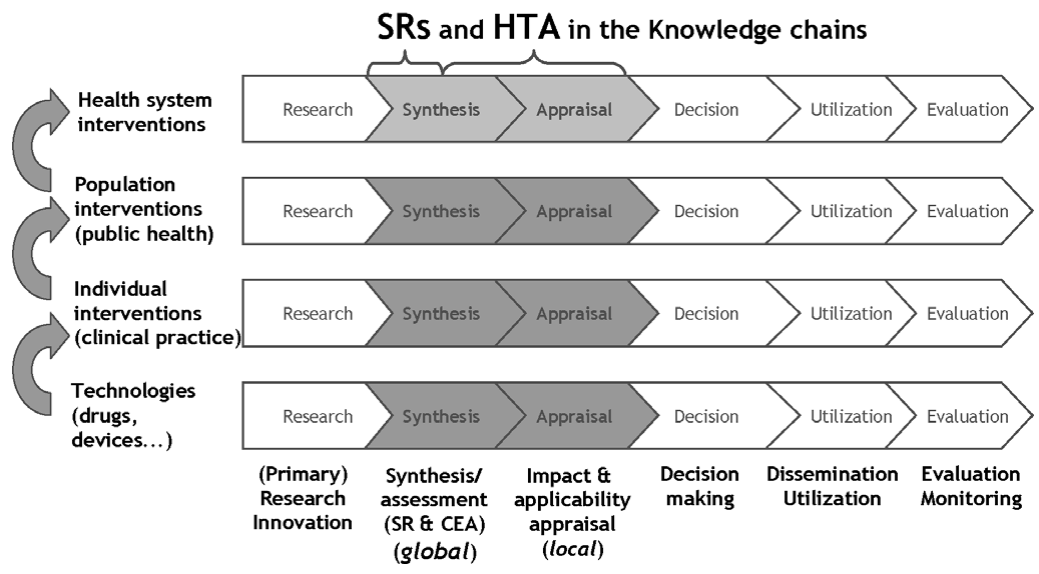

Figure 2. The knowledge chain. HTA, health technology assessment; SR, systematic review; CEA, cost-effectiveness assessment.

Chris Henshall was central in this development, although he also met some concern among some of us, who feared that the Society might move too far away from its scientific basis. It is important to have an ongoing scientific evaluation and academic debate in parallel to the HTA work. This is the point where I believe SMM might have done better during the first years. However, there were no academic experiences or traditions from this type of work in Norway at that time.

Also in Norway, HTA has progressively become linked to various policy-making processes. The Norwegian users have changed from mostly the clinical micro-level, to the broad amount of users coming from the management (meso) level. These changes reflect the reorganization and strengthening of a healthcare management system in Norway, with more professionalized personnel at the meso-levels in hospital management, heads of divisions in the Directorate for Health, in the Medicines Agency, and so on. Part of this management movement has also been to work evidence-based in their decision making, and translate HTA into policy, management, and practice decisions.

Formal agreements with health authorities (Figure 1) may create concern among other stakeholders about the HTA Centres' independence: where does the HTA activity as a source of factual knowledge on the benefits, risks, and costs of health care stop, where does it continue into regulation, or become normative in guidelines? We have had the intention to demonstrate clearly where our responsibility ends, and the authorities take over. This may have been more transparent when SMM was organized at the research foundation, SINTEF. Our initial strategy was to work mostly on clinical effectiveness and in close contact with clinicians, which created legitimacy at this level, but was hampered by no formal authority to take the HTA reports forward. It is an advantage to be a formal link in a knowledge chain, but it may induce concern as to the aims of HTA ("to save money in the health care"?). This is a general international experience, and in many countries the scientific documentation (HTA), and more normative decisions are handled separately, even within the same institution (National Institute for Clinical Excellence in the United Kingdom, for instance).

Some years ago, HTAi and INAHTA were challenged by WHO to place HTA into a knowledge chain (see Figure 2; The HTAi Annual Conference, Rome, 2005). This chain also covers a broader specter of "interventions," reflecting the involvement of more stakeholders. It introduces the need for broader scientific development. Efforts have been made to increase the involvement of health economics and cost-effectiveness analysis, now there is need for political science, social sciences, anthropology, and insight into organizational matters.

From The Norwegian Knowledge Centre, we will do our best to meet these challenges by drawing upon different disciplinary backgrounds and our national mandate to conduct knowledge synthesis for all types of healthcare-related interventions.

Mechanisms for monitoring and evaluation of the outcome from an evidence-based health care are part of the complete value chain; and we look forward to seeing how our work on monitoring the patients' experiences and clinical performance outcome indicators may bring new aspects into the usefulness of HTA.

\section{CONTACT INFORMATION}

Berit Mørland, DDS, PhD (berit.morland@nokc.no), Deputy Director, The Norwegian Knowledge Centre for the Health Services, Pb 7004, St Olavs plass, N-0130 Oslo, Norway 


\section{REFERENCES}

1. Brofoss KE, Søgnen R. Senter for medisinsk metodevurdering En evaluering. NIFU skriftserie nr 3/ 2001. (in Norwegian)

2. Evaluering av Nasjonalt kunnskapssenter for helsetjenesten Sluttrapport. Sosial-og helsedirektoratet, Oslo: October 15, 2007. (in Norwegian)

3. EUnetHTA. Executive Committee. Three years workplan. Copenhagen: EUnetHTA; 2006.

4. EUnetHTA. Executive Committee. Proposal for the EUNetHTA collaboration. Copenhagen: EUnetHTA; 2008.

5. Hofmann B. Toward a procedure for integrating moral issues in health technology assessment. Int J Technol Assess Health Care. 2005;21:312-318.

6. Jonsson E. Development of health technology assessment in Europe. A personal perspective. Int J Technol Assess Health Care. 2002;2:171-183.

7. Lund Håheim L, Mørland B. Implementation of recommendations from 31 Norwegian Health Technology Assessment Reports. Poster: 9th Biannual Meeting of the European Society for Medical Decision Meeting (ESMDM), Rotterdam, Nederland.

8. Lund Håheim L, Mørland B. Health technology assessment-a systematic approach for evaluation of the scientific documentation of medical technologies. Norsk Epidemiol. 2003;13:309314. (in Norwegian).

9. Lund Håheim L, Mørland B, Wisløff TF, Lyngstadaas A. Six years' experience with interdisciplinary review teams in health technology assessment in Norway. Int J Technol Assess Health Care. 2005;21:526-531.
10. Mørland B. Positron emission tomography (PET)—Diagnostic and clinical use. SMM report no. 6/2003. Oslo: The Norwegian Centre for Health Technology Assessment; 2003. (in Norwegian)

11. Mørland B. Experiences form 5 years of health technology assessment in Norway. Tidsskr Nor Laegeforen. 2003;123:12131215. (in Norwegian)

12. NIH Consensus Development Program. http://www.consensus. nih.gov/.

13. NHS Centre for Reviews and Dissemination. Undertaking systematic reviews of research on effectiveness. CRDs Guidance for those carrying out or commissioning reviews. CRD Report Number 4. 2nd ed. University of York, UK: NHS; March 2001.

14. Nordsletten L, Havelin LI, Indrekvam K, Aamodt A, Utvåg SE, Hviding K. Choice of primary hip replacement prosthesis. SMM report no. 6/2002. Oslo: The Norwegian Centre for Health Technology Assessment; 2002. (in Norwegian)

15. OECD. The OECD Health Project relating to new and emerging health related technologies (NEHRT). Paris: OECD; 2003.

16. Organisering av medisinsk teknologivurdering i Norge. Report, Sosial-og helsedepartementet, Juni 1996. (in Norwegian).

17. Piene H. Medisinsk forskning og teknologi. Utvikling og konsekvenser. NAVF; 1986. (in Norwegian).

18. Wiseth R, Gundersen T, Halvorsen S, Nordrehaug JE, Steigen T, Myhre KI. PCI treatment in acute infarction. SMM report no. 5/2002. Oslo: The Norwegian Centre for Health Technology Assessment; 2002. (in Norwegian) 